\title{
Safflower yellow B suppresses HepG2 cell injury induced by oxidative stress through the AKT/Nrf2 pathway
}

\author{
ZHONGYING MA*, CAIXIA LI*, YI QIAO*, CHENGTAO LU, JIANKANG LI, WEI SONG, \\ JIN SUN, XIAOHU ZHAI, JING NIU, QIAN REN and AIDONG WEN
}

Department of Pharmacy, Xijing Hospital, The Fourth Military Medical University, Xi'an, Shaanxi 710032, P.R. China

Received May 5, 2015; Accepted January 14, 2016

DOI: $10.3892 / \mathrm{ijmm} .2016 .2462$

\begin{abstract}
Oxidative stress plays an important role in the pathogenesis of various liver diseases. Safflower yellow B (SYB) has been reported to protect the brain against damage induced by oxidative stress; however, whether SYB can also protect hepatocytes from oxidative stress remains unknown. In the present study, to determine whether pre-treatment with SYB reduces hydrogen peroxide $\left(\mathrm{H}_{2} \mathrm{O}_{2}\right)$-induced oxidative stress in HepG2 cells, we investigated $\mathrm{H}_{2} \mathrm{O}_{2}$-induced oxidative damage to HepG2 cells treated with or without SYB. Cell viability was measured by MTT assay and cytotoxicity was evaluated by lactate dehydrogenase (LDH) assay. The activities of the antioxidant enzymes, glutathione peroxidase (GSH-Px) and superoxide dismutase (SOD) were determined using respective kits. Intracellular reactive oxygen species (ROS) accumulation in the HepG2 cells was monitored using the fluorescent marker, $2^{\prime}, 7^{\prime}$-dichlorodihydrofluorescein diacetate $\left(\mathrm{H}_{2} \mathrm{DCF}-\mathrm{DA}\right)$. Cell apoptosis was evaluated by determining the activity of caspase-3 and by Annexin V/propidium iodide (PI) double staining. Protein expression levels were measured by western blot analysis, and the levels of related cellular kinases were also determined. $\mathrm{H}_{2} \mathrm{O}_{2}$ induced pronounced injury to the HepG2 cells, as evidenced by increased levels of malondialdehyde (MDA) and ROS, the decreased activity of SOD and GSH-Px, the increased activitation of caspase-3 and cell apoptosis, and the loss of mitochondrial membrane potential. SYB significantly inhibited the damaging effects of $\mathrm{H}_{2} \mathrm{O}_{2}$, indicating that it protected the cells against $\mathrm{H}_{2} \mathrm{O}_{2}$-induced oxidative damage. Moreover, pre-treatment with SYB increased the expression of nuclear factor erythroid 2-related factor 2 (Nrf2), heme oxygenase $1(\mathrm{HO}-1)$ and $\mathrm{NAD}(\mathrm{P}) \mathrm{H}$ dehydrogenase, quinone 1 (NQO1) which are peroxiredoxins. SYB also significantly increased the phosphorylation of AKT. However,
\end{abstract}

Correspondence to: Professor Aidong Wen, Department of Pharmacy, Xijing Hospital, The Fourth Military Medical University, Changle West Road 127, Xi'an, Shaanxi 710032, P.R. China

E-mail: adwen-2012@hotmail.com

*Contributed equally

Key words: safflower yellow B, oxidative stress, HepG2 cells, Akt, nuclear factor erythroid 2-related factor 2 this inductive effect was blunted in the presence of the AKT inhibitor, LY294002. The findings of our study suggest that the activation of the AKT/Nrf2 pathway is involved in the cytoprotective effects of SYB against oxidative stress. Our findings provide new insight into the cytoprotective effects of SYB and the possible mechanisms underlying these effects. Thus, SYB may prove to be of therapeutic value for the treatment of various liver diseases.

\section{Introduction}

Reactive oxygen species (ROS) and other free radicals are produced during normal cell metabolism, a necessary and normal process, and they play important physiological roles $(1,2)$. However, under pathological conditions, the uncontrolled generation of ROS results in oxidative stress in cells, which subsequently leads to damage to different cellular structures, such as proteins, DNA and lipids (3). A proper balance between the formation of ROS and the antioxidant network is known to be essential for the regulation of biological processes. Clinical and experimental studies have suggested that oxidative stress is involved in the pathogenesis of a number of diseases $(4,5)$. The liver, due to its high metabolic activity and its anatomical positioning to receive blood from the gastrointestinal tract, is vulnerable to toxicity from a variety of drugs and environmental contaminants. ROS-induced mechanisms have, for instance, been related to different chronic liver diseases and hepatocellular carcinoma (HCC), and are induced by various risk factors for liver cancer, such as hepatitis B and $\mathrm{C}$ or aflatoxin-B, and thus may be a possible driving force in hepatocarcinogenesis $(6,7)$. Previous research has demonstrated that antioxidants are efficacious in preventing oxidative stress-related liver diseases and protecting cells from toxic insults (8). Therefore, there is increasing interest in the potential preventive/protective effects of exogenous antioxidants on oxidative stress-related hepatocellular disorders.

Carthamus tinctorius L. (safflower), which belongs to the Compositae family, has long been used in Chinese medicine in clinical settings for the treatment of various diseases due to its antioxidant properties. The chemical constituents in safflower have been reported to include lignans, flavonoids, triterpene alcohols and polysaccharides (9-12). Previous research has indicated that the main effective constituent of safflower is safflower yellow (SY), which is a flavonoid. SY consists of 
hydroxysafflower yellow A (HSYA), safflower yellow A (SYA) and safflower yellow B (SYB), as well as other chemicals (13).

Safflower has long been used in the treatment of cardiovascular diseases, and its anti-myocardial ischemic effects are well known. Safflower also exerts other pharmacological effects, including anticoagulant, antioxidant, neuroprotective and calcium antagonist effects (14). However, which component is responsible for these protective effects remains largely unknown. As one of the main components of safflower, SYB has been extensively used in the treatment of cardiocerebrovascular diseases in traditional Chinese medicine and has been shown to exert neuroprotective effects following permanent middle cerebral artery occlusion in rats (15). However, to the best of our knowledge, little research on the effects of SYB on liver preservation has been undertaken as of yet. Thus, the aim of the present study was to determine whether SYB is an effective component of safflower, and whether it can protect hepatocytes from oxidative damage. In our experiments, we used a control group treated with $\mathrm{N}$-acetylcysteine (NAC, $200 \mu \mathrm{M}$, a frequently used antioxidant in clinical settings), to establish whether SYB has antioxidant potential.

\section{Materials and methods}

Materials. SYB (purity $>98 \%$ ) was purchased from the Chinese National Institute for the Control of Pharmaceutical and Biological Products (Beijing, China). Dulbecco's modified Eagle's medium (DMEM) was obtained from Gibco Life Technologies (Grand Island, NY, USA) and the fetal bovine serum (FBS) we used was provided by Hangzhou Sijiqing Biological Engineering Materials Co., Ltd. (Hangzhou, China). NAC, 3-(4,5-dimethylthiazol-2-yl)-2,5-diphenyltetrazolium bromide (MTT), type I collagenase and western blot reagents were purchased from Sigma (St. Louis, MO, USA). The kits for the determination of lactate dehydrogenase (LDH), malondialdehyde (MDA), glutathione peroxidase (GSH-Px), superoxide dismutase (SOD) and caspase-3 activity were obtained from Nanjing Jiancheng Bioengineering Institute (Nanjing, China). Anti- $\beta$-actin primary (sc-7210), anti-AKT (sc-8312), anti-phosphorylated (p-)AKT (sc-33437), anti-heme oxygenase 1 (HO-1; sc-10789), anti-nuclear factor erythroid 2-related factor 2 (Nrf2; sc-7943) and anti-NAD $(\mathrm{P}) \mathrm{H}$ dehydrogenase, quinone 1 (NQO1; sc-25591) antibodies were obtained from Santa Cruz Biotechnology, Inc. (Santa Cruz, CA, USA). The caspase-3 assay kit was purchased from Chemicon International, Inc. (Temecula, CA, USA). 9-[4-[Bis[2-[(acetyloxy)methoxy]-2-oxoethyl]amino]3-[2-[2-[bis[2-[(acetyloxy)methoxy]-2-oxoethyl]amino]phenoxy] ethoxy]phenyl]-3,6-bis(dimethylamino)xanthylium bromide (Rhod-2 AM), DAPI, JC-1 and 2',7'-dichlorodihydrofluorescein diacetate $\left(\mathrm{H}_{2} \mathrm{DCF}-\mathrm{DA}\right)$ were purchased from Molecular Probes/ Invitrogen (Carlsbad, CA, USA).

Cell lines and cell culture. The human hepatoma cell line, HepG2, was obtained from the American Type Culture Collection (ATCC; Manassas, VA, USA) and cultured in DMEM supplemented with $10 \%$ FBS, glucose, penicillin and streptomycin. The HepG 2 cells were grown in $10-\mathrm{cm}$ cell culture dishes and incubated in a humidified atmosphere containing $5 \% \mathrm{CO}_{2}$ at $37^{\circ} \mathrm{C}$. The cells were seeded at a density of $4 \times 10^{4}$ cells $/ \mathrm{ml}$ in 96-well microplates for MTT assay, or 3x10 cells $/ \mathrm{ml}$ in 6-well microplates for MDA activity assay, antioxidant enzyme assays and other biochemical indicator determinations. The culture medium was changed every second day.

Cell treatments. The HepG2 cells were pre-treated with SYB $(50,100$ and $150 \mathrm{nmol} / \mathrm{l})$ for $24 \mathrm{~h}$ and then exposed to hydrogen peroxide $\left(\mathrm{H}_{2} \mathrm{O}_{2} ; 200 \mu \mathrm{mol} / \mathrm{l}\right)$ for a further $6 \mathrm{~h}$. Cells not exposed to $\mathrm{H}_{2} \mathrm{O}_{2}$ served as the controls, and cells exposed to $\mathrm{H}_{2} \mathrm{O}_{2}$ and not subjected to any treatments, served as the model group. In order to determine the ability of SYB to protect the cells from damage, the cells were also treated with NAC $(200 \mu \mathrm{M})$, a well-characterized chemoprotective compound. In addition, in order to determine the role of AKT in the effects of SYB, the cells were treated with the AKT inhibitor, LY294002 (10 $\mu \mathrm{M}$; purchased from Sigma).

Cell viability and cytotoxicity assays. Cell viability was determined by MTT assay. The cells were seeded at a density of $1 \times 10^{4}$ cells/well in 96-well plates. After the cells were subjected to the different treatments, $20 \mu \mathrm{l}$ MTT solution $(5 \mathrm{mg} / \mathrm{ml})$ was added to each well and the final concentration at $5 \mathrm{mg} / \mathrm{ml}$ was maintained for $4 \mathrm{~h}$ at $37^{\circ} \mathrm{C}$. Subsequently, the medium was removed and DMSO $(150 \mathrm{ml})$ was added to each well. The optical density (OD) was determined spectrophotometrically at $490 \mathrm{~nm}$ using a microplate reader (Infinite M200 PRO; Tecan, Männedorf, Switzerland), and the cell survival ratio was expressed as a percentage of the control.

Cytotoxicity was evaluated by LDH leakage assay after collecting the culture medium, and the cells were scraped in phosphate-buffered saline (PBS) after the cells were subjected to the different treatments. The cells were first sonicated to ensure the cell membrane broke down to release the total amount of LDH; subsequently, centrifugation $(1,000 \mathrm{x}$ g for $15 \mathrm{~min}$ ) to clear up the cell sample was undertaken. LDH leakage was estimated from the ratio between the LDH activity in the culture medium and that of the whole cell content.

Determination of intracellular ROS accumulation. Intracellular ROS accumulation in the HepG2 cells was monitored using the fluorescent marker, $\mathrm{H}_{2}$ DCF-DA. Briefly, the HepG2 cells $\left(1 \times 10^{5}\right.$ cells/well) were seeded into 6-well plates and pre-treated with or without NAC or increasing concentrations of SYB (50, 100 and $150 \mathrm{nmol} / \mathrm{l})$ for $24 \mathrm{~h}$. Oxidative stress was induced by the addition of $\mathrm{H}_{2} \mathrm{O}_{2}$ to the culture medium for $30 \mathrm{~min}$. At the end of the incubation period, the culture supernatant was removed and the cells were washed twice with PBS. $\mathrm{H}_{2}$ DCF-DA $(10 \mu \mathrm{M})$ was mixed with $500 \mu \mathrm{l}$ DMEM and added to the culture plate. Following incubation for $30 \mathrm{~min}$, the relative fluorescence intensity was quantified using a fluorescence spectrophotometer (Hidex Oy, Turku, Finland) at $485 / 535 \mathrm{~nm}$ (A485/535). The percentage of ROS generation was calculated as follows: (A485/535 of treated cells/A485/535 of untreated cells) $\mathrm{x} 100$.

Measurement of GSH-Px and SOD activities. The activities of antioxidant enzymes were determined according to the instructions provided with the assay kits (Nanjing Jiancheng Bioengineering Institute). Briefly, after the cells were subjected to the different treatments, they were washed twice with PBS, resuspended in $1 \mathrm{ml} 0.1 \mathrm{M}$ phosphate buffer ( $\mathrm{pH}$ 7.4) and 
homogenized. The homogenate was centrifuged at 2,200 x g for $10 \mathrm{~min}$ at $4{ }^{\circ} \mathrm{C}$, and the supernatants were collected following centrifugation for the following analyses. SOD activity was assayed at $560 \mathrm{~nm}$ on the basis of its ability to inhibit the oxidation of hydroxylamine via the superoxide anion from the xanthine oxidase system. GSH-Px activity was measured at $412 \mathrm{~nm}$ on the basis of the rate of oxidation of the reduced glutathione to oxidized glutathione by $\mathrm{H}_{2} \mathrm{O}_{2}$ under the catalyst, GSH-Px. The protein content in the cell lysate was determined using Coomassie blue staining solution (from Nanjing Jiancheng Bioengineering Institute).

Apoptosis. Apoptosis was evaluated by Annexin V/propidium iodide (PI) double staining assay. Briefly, the cells were trypsinized following a wash in PBS and resuspended in $400 \mu \mathrm{l}$ binding buffer. Subsequently, $5 \mu \mathrm{l}$ Annexin V-FITC and $5 \mu \mathrm{l}$ PI $(50 \mu \mathrm{M})$ working solution were added to every $200 \mu \mathrm{l}$ cell suspension. The cells were incubated at room temperature for $20 \mathrm{~min}$ in the dark and analyzed by flow cytometry. Annexin V and PI emissions were detected in the FL1-H and FL2-H channels of a FACSCalibur flow cytometer (BD Biosciences, San Jose, CA, USA) using emission filters of 525 and $575 \mathrm{~nm}$, respectively. The number of each type of cells was expressed as percentages of the number of total stained cells. Data were acquired using CellQuest software and analyzed by ModFit software.

Apoptosis was also evaluated by examining the activation of caspase-3. The cells were lysed in buffer containing $5 \mathrm{mM}$ Tris, $\mathrm{pH} \mathrm{8,} 20 \mathrm{mM}$ ethylenediaminetetraacetic acid (EDTA) and $0.5 \%$ Triton X-100 (both from Sigma). The reaction mixture contained $20 \mathrm{mM}$ HEPES, pH 7, $10 \%$ glycerol, $2 \mathrm{mM}$ dithiothreitol and $30 \mu \mathrm{g}$ protein per well, as well as $20 \mu \mathrm{M}$ Ac-DEVD-AMC as substrate. The enzymatic activity was determined by measuring fluorescence at an excitation wavelength of $380 \mathrm{~nm}$ and an emission wavelength of $440 \mathrm{~nm}$ (BioTek Instruments, Inc., Winooski, VT, USA).

Protein extraction and western blot analysis. The cells were lysed with either mammalian protein extraction reagent or nuclear and cytoplasmic extraction reagent kits (Pierce Biotechnology, Rockford, IL, USA). Protein concentrations were determined using Bio-Rad protein assay reagent (Bio-Rad Laboratories, Hercules, CA, USA). Equal amounts of protein samples (30 $\mu \mathrm{g})$ were separated by $10 \%$ SDS-PAGE, and the separated proteins were transferred onto polyvinylidene fluoride (PVDF) membranes (Bio-Rad Laboratories) overnight. The transferred protein membranes were blocked with $5 \%$ non-fat dried milk for $30 \mathrm{~min}$, followed by incubation with specific primary antibodies ( $\beta$-actin, AKT, p-AKT, HO-1, Nfr2 and NQO1) overnight at $4^{\circ} \mathrm{C}$, and either horseradish peroxidase-conjugated goat anti-rabbit or anti-mouse antibodies for $1 \mathrm{~h}$ at $37^{\circ} \mathrm{C}$. The blots were detected using VL Chemi-Smart 3000 (Viogene-Biotek, Sunnyvale, CA, USA) with enhanced chemiluminescence (ECL) western blotting reagent (Millipore, Billerica, MA, USA). $\beta$-actin was used as a loading control.

Measurement of mitochondrial membrane potential $(\Delta \Psi m)$. $\Delta \Psi \mathrm{m}$ in the HepG2 cells was evaluated by 5,5',6,6'-tetrachloro1,1'3,3'-tetraethylbenzimidazolyl-carbocyanine iodide (JC-1) staining. The fluorescent dye, JC-1, exhibits potential dependent accumulation in mitochondria by a fluorescence emission shift from green (monomeric form, indicating depolarized/low $\Delta \Psi \mathrm{m}$ ) to red (aggregated form, indicating polarized/normal $\Delta \Psi \mathrm{m}$ ). In this study, the HepG2 cells $\left(1 \times 10^{5}\right.$ cells/well) were seeded in 35-mm dishes and pre-treated with or without increasing concentrations of SYB or NAC for $24 \mathrm{~h}$. Oxidative stress was induced by the addition of $\mathrm{H}_{2} \mathrm{O}_{2}$ into the culture medium. At the end of the incubation period, the culture supernatant was removed and the cells were washed twice with PBS. The cells were incubated with JC-1 (Qcbio Science \& Technologies Co., Ltd., Shanghai, China) staining liquid for $20 \mathrm{~min}$ at $37^{\circ} \mathrm{C}$, washed 3 times with JC-1 staining buffer and examined under a confocal microscope (SP5-FCS; Leica Microsystems, Wetzlar, Germany).

Measurement of mitochondrial calcium. To follow $\mathrm{H}_{2} \mathrm{O}_{2}$-induced intramitochondrial calcium trafficking, mitochondrial calcium was estimated by co-incubating the cells with a mitochondria-permeant calcium fluorophore, Rhod-2 AM (2 $\mu \mathrm{M})$. For confocal images, $2 \times 10^{4}$ cells were seeded onto a glass coverslip, pre-treated with SYB for $24 \mathrm{~h}$, and then subjected to $\mathrm{H}_{2} \mathrm{O}_{2}$. Subsequently, the cells were stained with Rhod-2 AM $(2 \mu \mathrm{M})$, fixed with $4 \%$ buffered paraformaldehyde, washed 3 times with PBS and mounted with antifade on a glass slide for image acquisition using a confocal microscope (SP5-FCS; Leica Microsystems). The untreated unstained cells served as the negative controls and untreated fluorophore-loaded cells served as the controls for background correction for the confocal experiments.

Statistical analysis. All values are expressed as the means \pm SD. A one-way analysis of variance test, followed by Bonferoni's correction, was carried out to test for any differences between the mean values of all groups. A P-value $<0.05$ was considered to indicate a statistically significant difference.

\section{Results}

$S Y B$ protects cells against $\mathrm{H}_{2} \mathrm{O}_{2}$-induced cell damage. In order to elucidate the mechanisms responsible for the protective effects of SYB against $\mathrm{H}_{2} \mathrm{O}_{2}$-induced cell damage, the human hepatoma HepG2 cells were pre-treated with SYB (50, 100 and $150 \mathrm{nmol} / \mathrm{l})$ for $24 \mathrm{~h}$ and then exposed to $\mathrm{H}_{2} \mathrm{O}_{2}(200 \mu \mathrm{mol} / \mathrm{l})$ for a further $6 \mathrm{~h}$. Concentrations of SYB which did not cause any measurable adverse effects to the cells (data not shown) were selected. The effects of pre-treatment with SYB on cell viability and cell integrity following exposure to $\mathrm{H}_{2} \mathrm{O}_{2}$ were determined by MTT assay and LDH leakage assay, respectively, and the ability of SYB to protect the cells from damage was compared to a well-characterized chemoprotective compound, NAC $(200 \mu \mathrm{M})$. The results revealed that pre-treatment with SYB for $24 \mathrm{~h}$ protected the HepG2 cells from subsequent $\mathrm{H}_{2} \mathrm{O}_{2}$-induced damage in a concentration-dependent manner, as shown by the measurement of cell viability by MTT assay (Fig. 1A). Similarly, the LDH leakage assay revealed that treatment with SYB for $24 \mathrm{~h}$ prior to exposure to $\mathrm{H}_{2} \mathrm{O}_{2}$ decreased LDH leakage from the cells, indicating that SYB enabled the HepG2 cells to maintain cell integrity. The protective effects of SYB against LDH leakage also occurred in dose-dependent manner (Fig. 1B). The protective effects of SYB $(150 \mathrm{nmol} / \mathrm{l})$ were equal or greater to those exerted by NAC $(200 \mu \mathrm{M})$. 

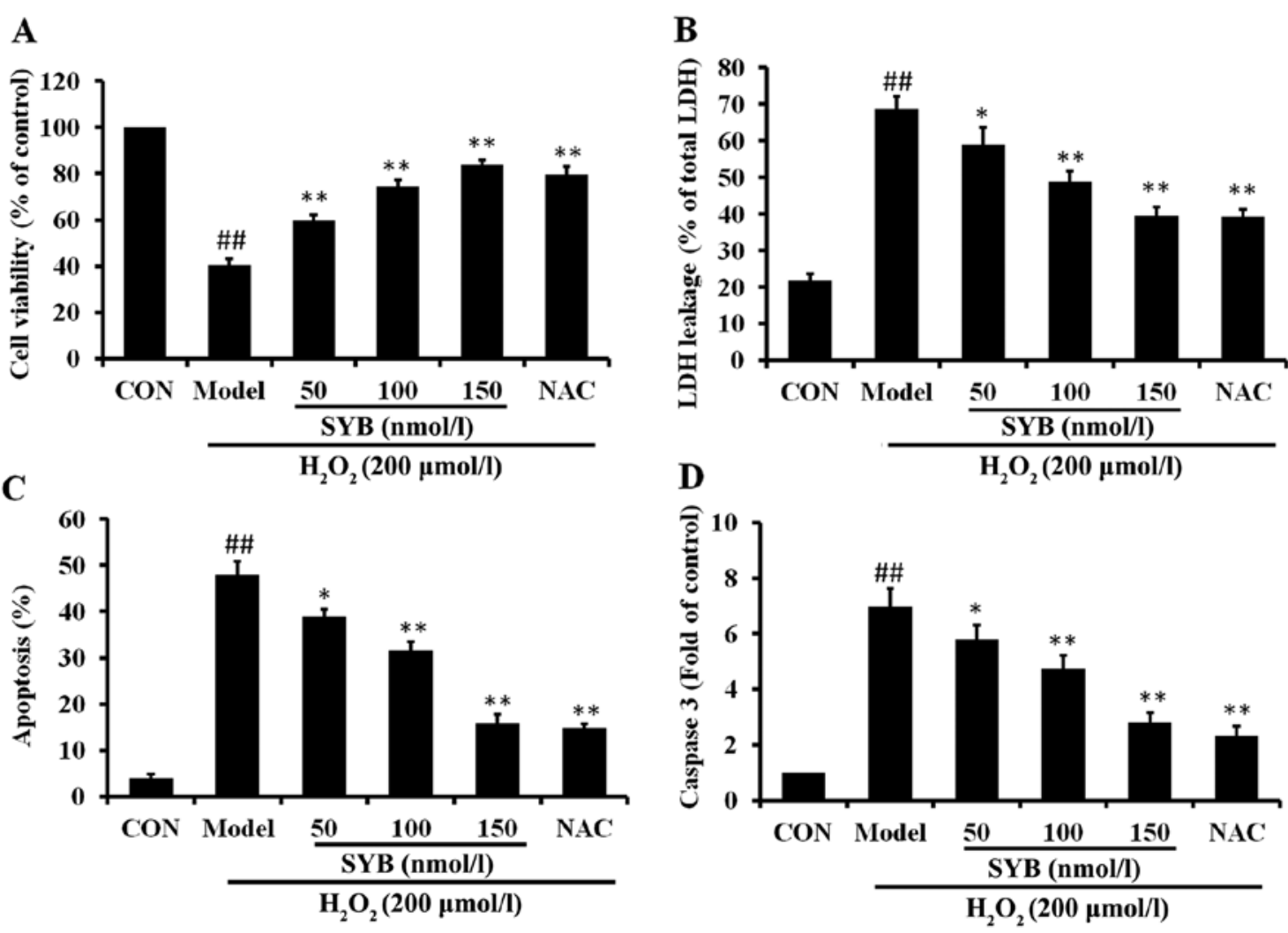

Figure 1. Effects of safflower yellow B (SYB) on $\mathrm{H}_{2} \mathrm{O}_{2}$-induced cell injury. (A) Cells were treated with SYB (50, 100 and $\left.150 \mathrm{nmol} / \mathrm{l}\right)$ for $24 \mathrm{~h}$ before being treated with $\mathrm{H}_{2} \mathrm{O}_{2}(200 \mu \mathrm{mol} / 1)$, and cell viability was assayed by MTT assay. The results are expressed as percentages of the control. (B) HepG2 cells were incubated with or without SYB $(50,100$ and $150 \mathrm{nmol} / \mathrm{l})$ for $24 \mathrm{~h}$ before being treated with $\mathrm{H}_{2} \mathrm{O}_{2}(200 \mu \mathrm{mol} / \mathrm{l})$, and lactate dehydrogenase (LDH) leakage (\% of total LDH) was assayed as described in the Materials and methods. (C) Cell apoptosis was determined by Annexin V-FITC/propidium iodide (PI) double staining. (D) SYB attenuated the $\mathrm{H}_{2} \mathrm{O}_{2}$-induced changes in the caspase-3 levels. Data represent the means $\pm \mathrm{SD}$. ${ }^{\# \#} \mathrm{P}<0.01$, statistically significant difference between model vs. control group; ${ }^{*} \mathrm{P}<0.05$ and ${ }^{* *} \mathrm{P}<0.01$, statistically significant difference between $\mathrm{SYB}$ vs. model group.

To determine whether SYB exerts anti-apoptotic effects, Annexin V-FITC/PI double staining and caspase-3 assay were performed. The results of flow cytometric detection revealed that $\mathrm{H}_{2} \mathrm{O}_{2}$ induced a significant increase in the apoptosis of the HepG2 cells compared with the control group, and that apoptosis was markedly decreased by pre-treatment with SYB (Fig. 1C). As the sequential activation of caspases plays a central role in the execution phase of cell apoptosis (16), the activation of caspase- 3 was examined in this study. Exposure of the HepG2 cells to $\mathrm{H}_{2} \mathrm{O}_{2}$ induced a significant increase in the level of caspase-3 compared to the control group; however, pre-treatment with SYB or NAC significantly decreased the level of caspase-3 (Fig. 1D). These results suggested that SYB protected the $\mathrm{HepG} 2$ cells against apoptosis induced by $\mathrm{H}_{2} \mathrm{O}_{2}$.

Effects of SYB on $\triangle \Psi m$. In many systems, apoptosis is associated with the loss of $\Delta \Psi \mathrm{m}$, which may be regarded as a limiting factor in the apoptotic pathway (17). Excessive ROS production, which leads to a decrease in $\Delta \Psi \mathrm{m}$, may also induce apoptotic cell death (18). In light of these facts, in this study, we assessed whether there was any reduction in $\Delta \Psi \mathrm{m}$ in the $\mathrm{H}_{2} \mathrm{O}_{2}$-exposed cells using the potential-sensitive dye, JC-1. The exposure of the HepG2 cells to $\mathrm{H}_{2} \mathrm{O}_{2}$ for $6 \mathrm{~h}$ resulted in a decrease in the ratio of red to green fluorescence, as detected by confocal microscopy when compared to the control cells, and treatment with SYB or NAC restored this ratio (Fig. 2).
$S Y B$ reduces $\mathrm{H}_{2} \mathrm{O}_{2}$-dependent intracellular $\mathrm{ROS}$ production and MDA formation and increases antioxidant enzyme activity. To investigate the mechanisms through which SYB protects cells against $\mathrm{H}_{2} \mathrm{O}_{2}$-induced damage, the effects of pre-treatment with SYB on the intracellular ROS levels were determined. The HepG2 cells were pre-treated with SYB for $24 \mathrm{~h}$, and then exposed to $200 \mu \mathrm{mol} / 1 \mathrm{H}_{2} \mathrm{O}_{2}$ for $6 \mathrm{~h}$, and the ROS levels were measured by DCF fluorescence. The results revealed that exposure to $\mathrm{H}_{2} \mathrm{O}_{2}$ induced a rapid and significant increase in the intracellular ROS levels, when compared to the untreated controls (Fig. 3A). Pre-treatment of the cells with SYB for $24 \mathrm{~h}$ significantly decreased the $\mathrm{H}_{2} \mathrm{O}_{2}$-induced production of intracellular ROS compared with the $\mathrm{H}_{2} \mathrm{O}_{2}$-exposed cells not treated with SYB (model group; $\mathrm{P}<0.05$ ). To examine the effects of $\mathrm{SYB}$ on $\mathrm{H}_{2} \mathrm{O}_{2}$-induced lipid peroxidation, the level of MDA in the cells was measured. Exposure of the HepG2 cells to $\mathrm{H}_{2} \mathrm{O}_{2}$ markedly increased the intracellular MDA levels (Fig. 3B). When the cells were pre-treated with SYB, the increase in the MDA levels induced by $\mathrm{H}_{2} \mathrm{O}_{2}$ was significantly prevented in a dose-dependent manner.

GSH-Px and SOD activity was measured as an index of the enzymatic antioxidant defense system in HepG2 cells during oxidative stress. The HepG2 cells were exposed to $200 \mu \mathrm{mol} / 1$ $\mathrm{H}_{2} \mathrm{O}_{2}$ and either pre-treated or not with SYB or NAC. The results revealed that exposure to $\mathrm{H}_{2} \mathrm{O}_{2}$ markedly decreased the GSH-Px and SOD levels compared to the control group. More 


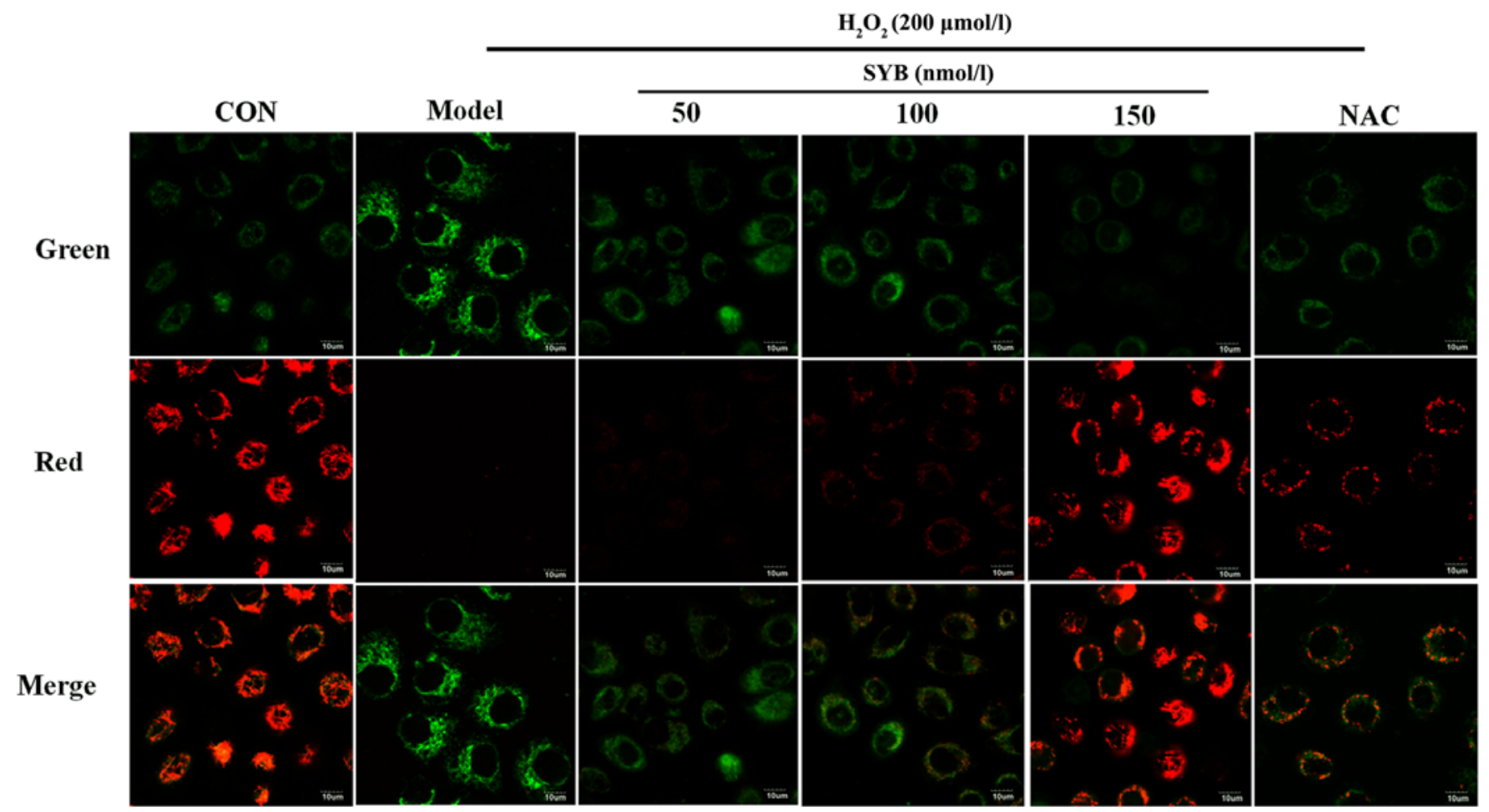

Figure 2. Effects of safflower yellow B (SYB) on mitochondrial membrane potential. Morphology of HepG2 cells following incubation with $\mathrm{H}_{2} \mathrm{O}_{2}$ for $6 \mathrm{~h}$ with or without pre-treatment with SYB $(50,100$ and $150 \mathrm{nmol} / \mathrm{l})$ or N-acetylcysteine (NAC; $200 \mu \mathrm{M})$ for $24 \mathrm{~h}$.

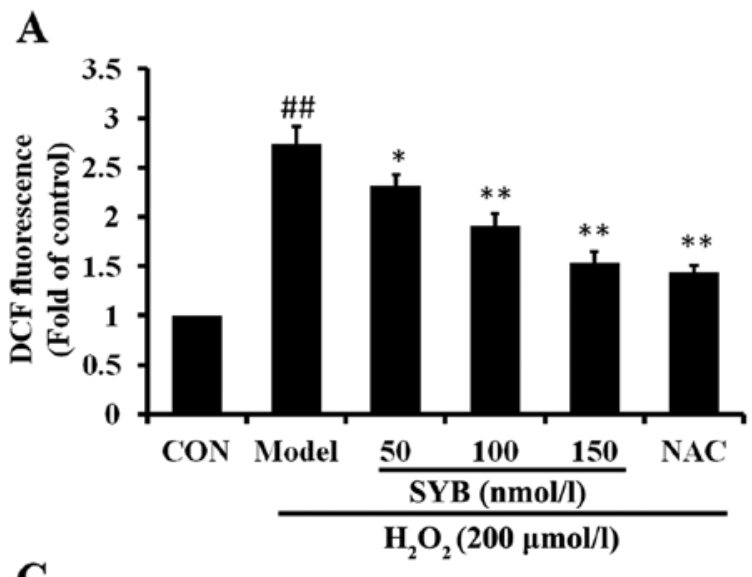

C

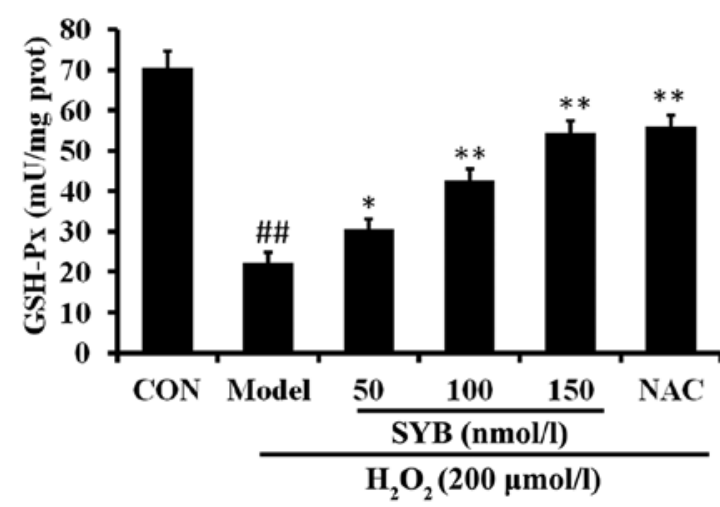

B

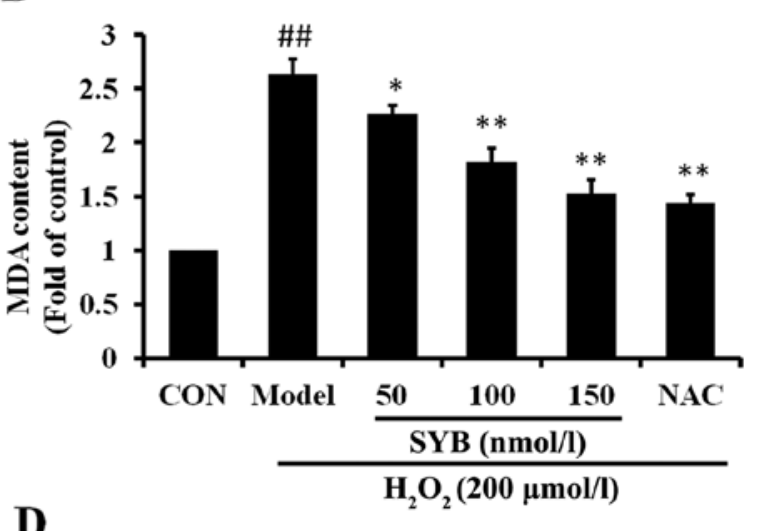

D

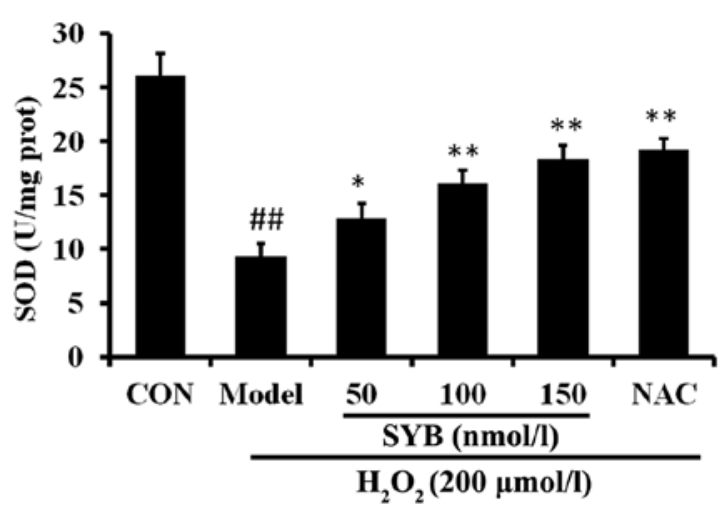

Figure 3. Safflower yellow B (SYB) reduces $\mathrm{H}_{2} \mathrm{O}_{2}$-dependent intracellular reactive oxygen species (ROS) production and malondialdehyde (MDA) formation and increases antioxidant enzyme activity. (A) Cells were treated with SYB $(50,100$ and $150 \mathrm{nmol} / \mathrm{l})$ or N-acetylcysteine (NAC; $200 \mu \mathrm{M})$ for $24 \mathrm{~h}$ before being treated with $\mathrm{H}_{2} \mathrm{O}_{2}(200 \mu \mathrm{mol} / 1)$, and then 2',7'-dichlorodihydrofluorescein diacetate $\left(\mathrm{H}_{2} \mathrm{DCF}-\mathrm{DA} ; 10 \mu \mathrm{M}\right)$ was mixed with $500 \mu 1$ DMEM and added to the culture plate.

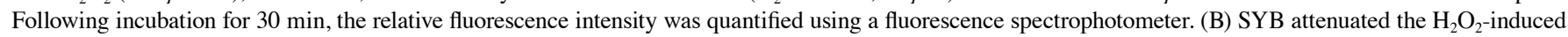
changes in the MDA content. Effects of SYB on the activities of (C) GSH-Px and (D) superoxide dismutase (SOD) in HepG2 cells. Data represent the means \pm SD. ${ }^{\# \#} \mathrm{P}<0.01$, statistically significant difference between model vs. control group; ${ }^{*} \mathrm{P}<0.05$ and ${ }^{* *} \mathrm{P}<0.01$, statistically significant difference between $\mathrm{SYB}$ vs. model group. 


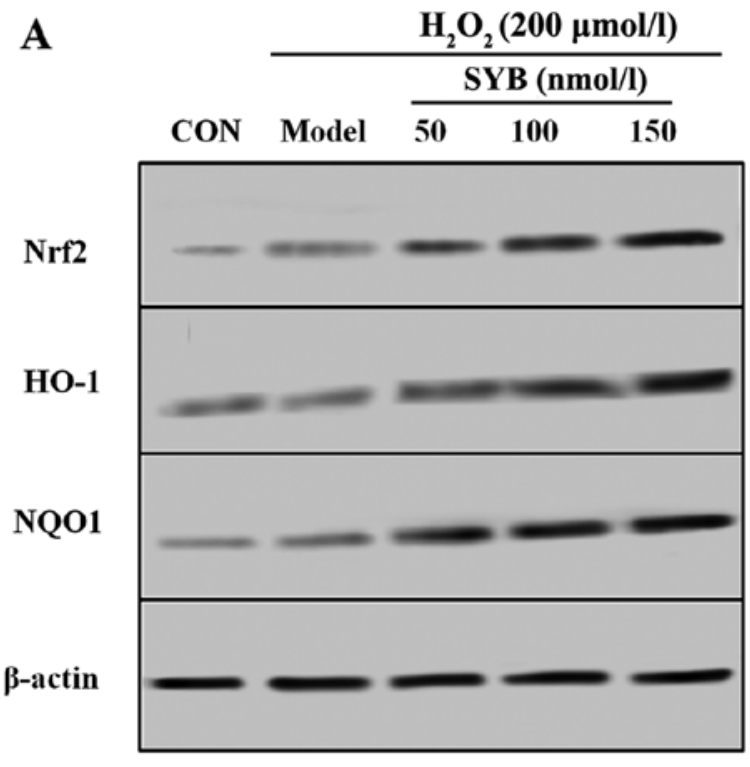

D
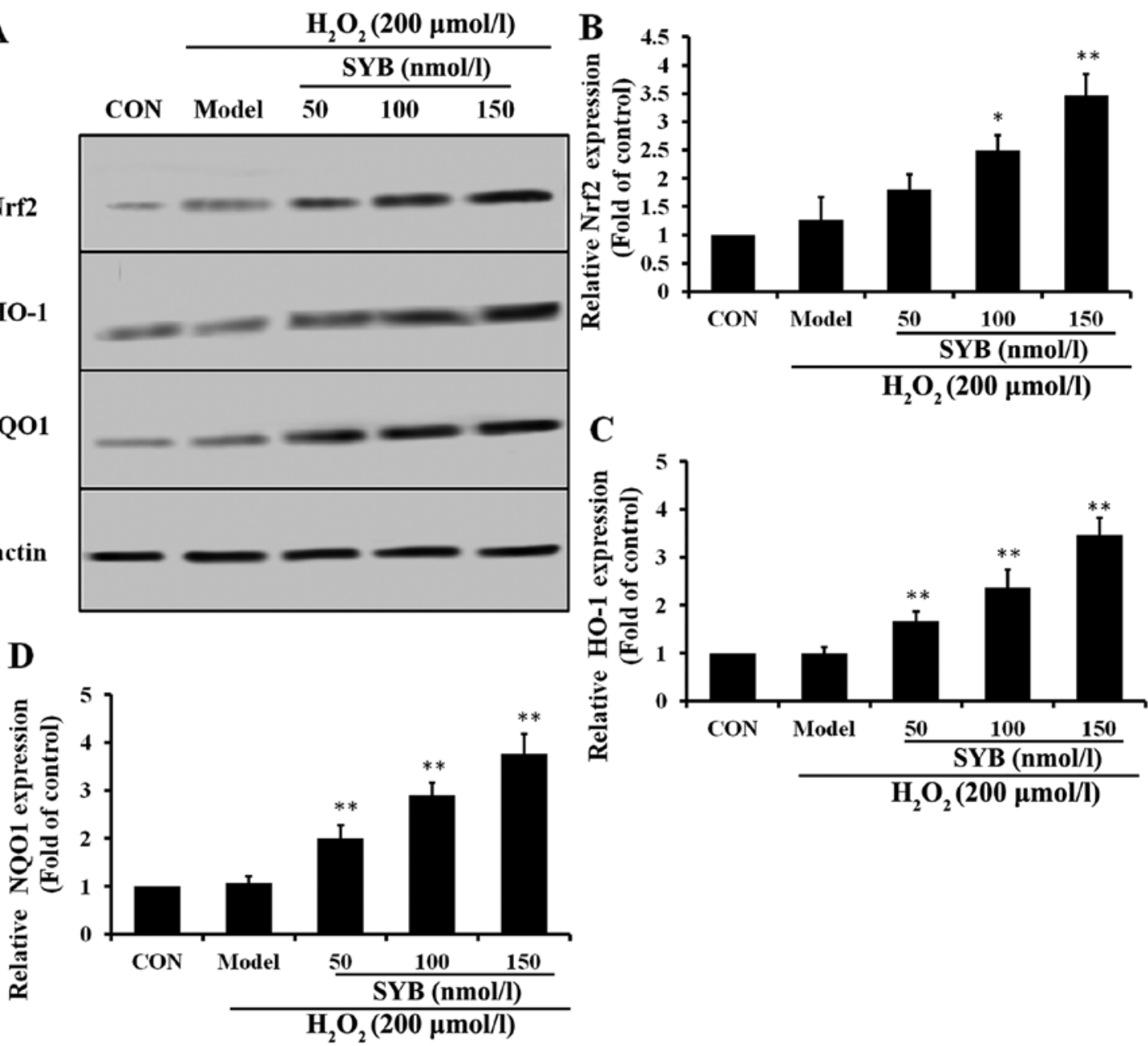

Figure 4. Effects of safflower yellow B (SYB) on nuclear factor erythroid 2-related factor 2 (Nrf2)-mediated antioxidant defense proteins in HepG2 cells. Cells were treated with SYB $(50,100$ and $150 \mathrm{nmol} / \mathrm{l})$ for $24 \mathrm{~h}$ prior to treatment with $\mathrm{H}_{2} \mathrm{O}_{2}(200 \mu \mathrm{mol} / \mathrm{l})$. Total cell lysates were prepared and subjected to western blot analysis to monitor the expression levels of antioxidant proteins, namely Nrf2, heme oxygenase 1 (HO-1) and NAD(P)H dehydrogenase, quinone 1 (NQO1). $\beta$-actin served as an internal control. (A) Western blot analysis of Nrf2, HO-1 and NQO1 expression. Quantitative representations of western blot analysis of (B) Nrf2, (C) HO-1 and (D) NQ01. Data represent the means \pm SD. ${ }^{*} \mathrm{P}<0.05$ and ${ }^{* *} \mathrm{P}<0.01$, statistically significant difference between $\mathrm{SYB}$ vs. model group.

significantly, the results revealed that pre-treatment with SYB increased the GSH-Px and SOD levels, which were decreased following exposure to $\mathrm{H}_{2} \mathrm{O}_{2}$ (Fig. $3 \mathrm{C}$ and D). These data suggest that SYB exerts its protective effects by enhancing the the antioxidant capability of the cells.

Effects of SYB on Nrf2-mediated antioxidant defense system proteins in Hep 2 cells. To examine the effects of SYB on $\mathrm{Nrf} 2$ activity, we first treated the HepG2 cells with various concentrations of SYB for $24 \mathrm{~h}$ and then examined the dose-response effects of SYB on the expression of Nrf2. Pre-treatment with SYB gradually increased cytosolic Nrf2 expression in a dose-dependent manner (Fig. 4A and B). Activated Nrf2 binds to antioxidant response element (ARE) sites and causes the upregulation of its target genes (19). It is well known that HO-1 and NQO1 are two major antioxidant enzymes that play an important role in $\mathrm{H}_{2} \mathrm{O}_{2}$-induced antioxidant defense in hepatic cells (20). Thus, we hypothesized that the inhibitory effects of SYB on $\mathrm{H}_{2} \mathrm{O}_{2}$-induced hepatic enzyme leakage and/ or the augmentation of GSH-Px and SOD levels result from the induction of antioxidant genes, such as HO-1 and NQO1.
As expected, we observed that SYB significantly increased the HO-1 and NQO1 expression levels in the $\mathrm{H}_{2} \mathrm{O}_{2}$-exposed HepG2 cells in a dose-dependent manner (Fig. 4C and D). These data clearly indicate that the cytoprotective effects of SYB are mediated through Nrf2.

Role of AKT in the SYB-induced upregulation of Nrf2 and $H O-1$. It has previously been noted that AKT is involved in the induction of Nrf2/ARE-driven gene expression (21). Thus, in order to identify which signaling cascade controls Nrf2 activation and the induction of HO-1 expression in the SYB-treated HepG2 cells, the activation of the AKT pathway was investigated. As shown in Fig. 5A, in the HepG2 cells exposed to $\mathrm{H}_{2} \mathrm{O}_{2}$ (model group), the reduced activation of AKT was observed; however, treatment with SYB significantly increased the phosphorylation of AKT in a dose-dependent manner. Subsequently, we examined whether SYB enhances Nrf2 expression through the AKT pathway. Treatment of the cells with the AKT inhibitor, LY294002, suppressed the SYB-induced phosphorylation of AKT in the HepG2 cells exposed to $\mathrm{H}_{2} \mathrm{O}_{2}$. Moreover, the inhibition of the AKT 
A
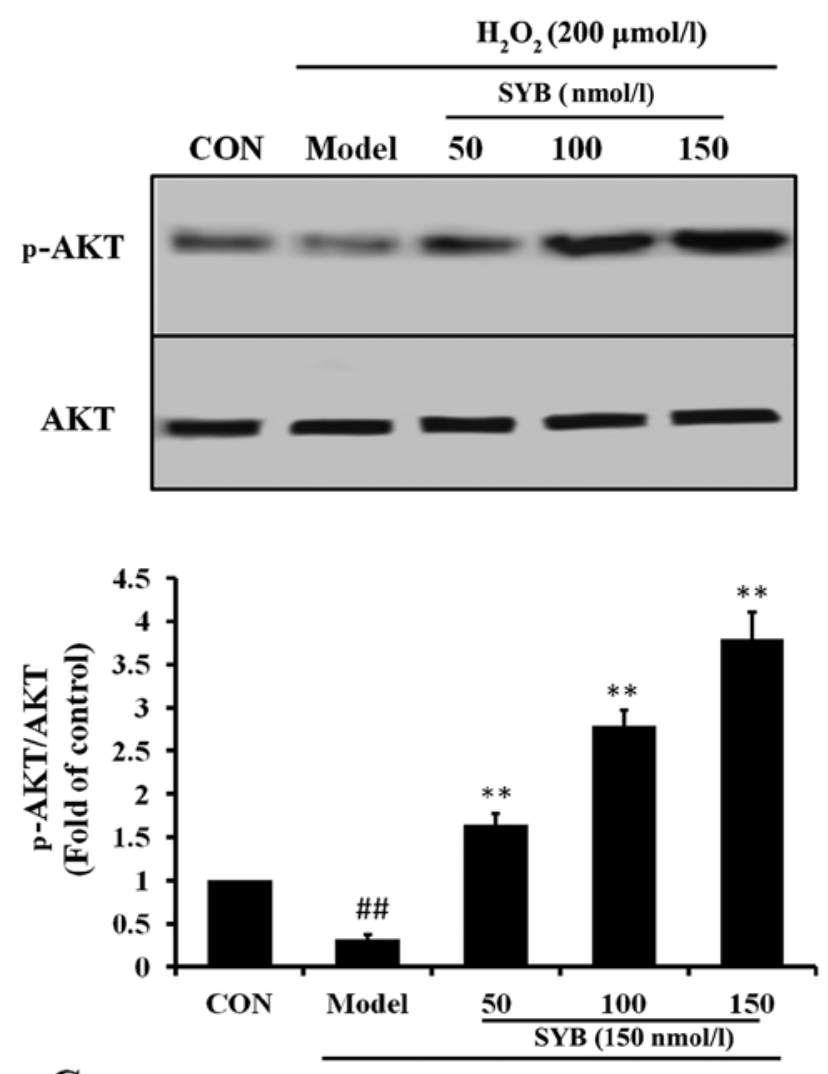

C

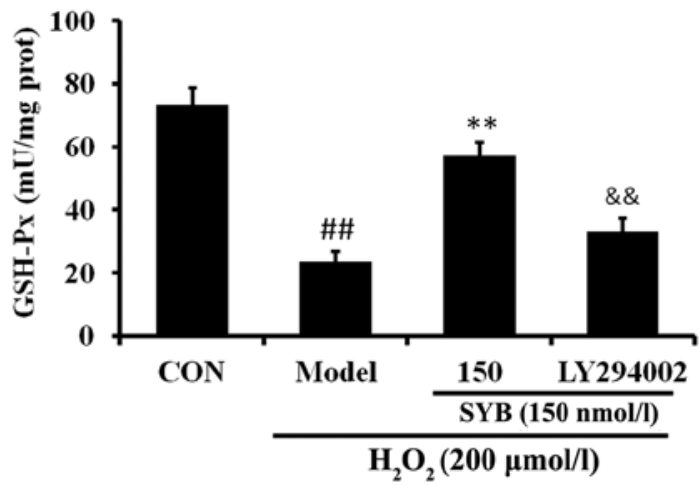

B
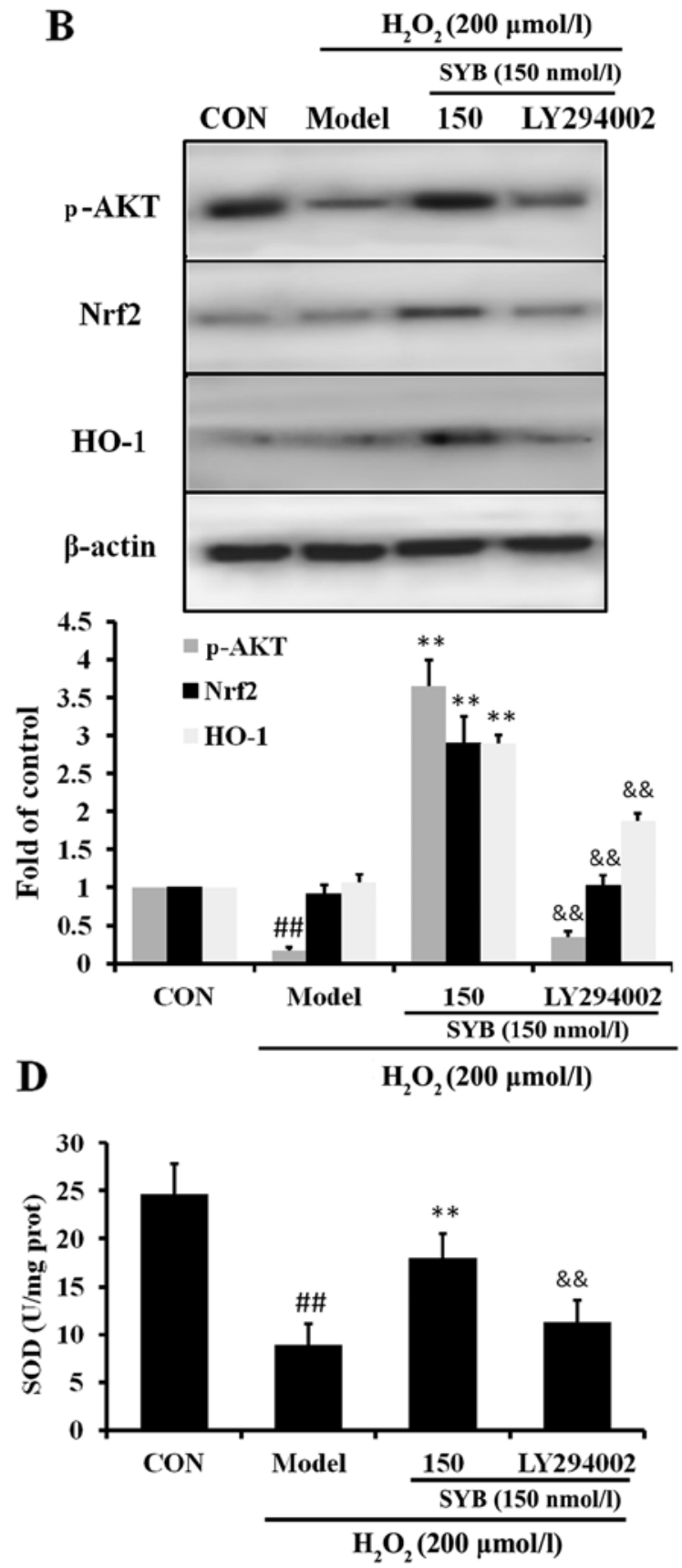

Figure 5. Role of AKT in safflower yellow B (SYB)-induced nuclear factor erythroid 2-related factor 2 (Nrf2) and heme oxygenase 1 (HO-1) upregulation. (A) Effects of SYB (50, 100 and $150 \mathrm{nmol} / \mathrm{l})$ on AKT protein expression in HepG2 cells exposed to $\mathrm{H}_{2} \mathrm{O}_{2}(200 \mu \mathrm{mol} / \mathrm{l})$. (B) Role of AKT in SYB-induced Nrf2 expression. Cells were pre-treated with SYB $(150 \mathrm{nmol} / \mathrm{l})$ or LY294002 $(10 \mu \mathrm{M})$ for $24 \mathrm{~h}$, then exposed to $\mathrm{H}_{2} \mathrm{O}_{2}(200 \mu \mathrm{mol} / \mathrm{l})$. Total cell lysates were prepared and subjected to western blot analysis. $\beta$-actin was used as a loading control. (C) GSH-Px and (D) superoxide dismutase (SOD) levels were measured using respective kits. Data represent the means $\pm \mathrm{SD} .{ }^{\# \#} \mathrm{P}<0.01$, statistically significant difference between model vs. control group; ${ }^{* *} \mathrm{P}<0.01$, statistically significant difference between SYB vs. model group; ${ }^{\&}{ }^{\&} \mathrm{P}<0.01$, statistically significant difference between LY294002 vs. SYB group.

pathway by LY294002 markedly reduced the capacity of SYB to increase Nrf2 and HO-1 expression (Fig. 5B), as well as the GSH-Px and SOD levels (Fig. 5C and D). Consistently, the inhibition of AKT by LY294002 also eliminated the SYB-induced cytoprotective effects against $\mathrm{H}_{2} \mathrm{O}_{2}$-induced cell death; the cell viability rate decreased, LDH leakage increased and calcium overload was noted in the mitochondria following treatment with LY294002 (Fig. 6). These results suggest that SYB induces the activation of Nrf2/HO-1 and the antioxidant defense machinery by activating the AKT pathway.

\section{Discussion}

Oxidative stress is an abnormal phenomenon that occurs inside the human body when the production of free radicals exceeds the antioxidant capacity. The excessive production of free radicals and other ROS damages essential macromolecules of the cell, leading to the development of a number of human diseases, including atherosclerosis, rheumatoid arthritis, inflammation, cancer and neurodegenerative diseases (22). Oxidative stress associated with the formation of ROS plays an important role 
A

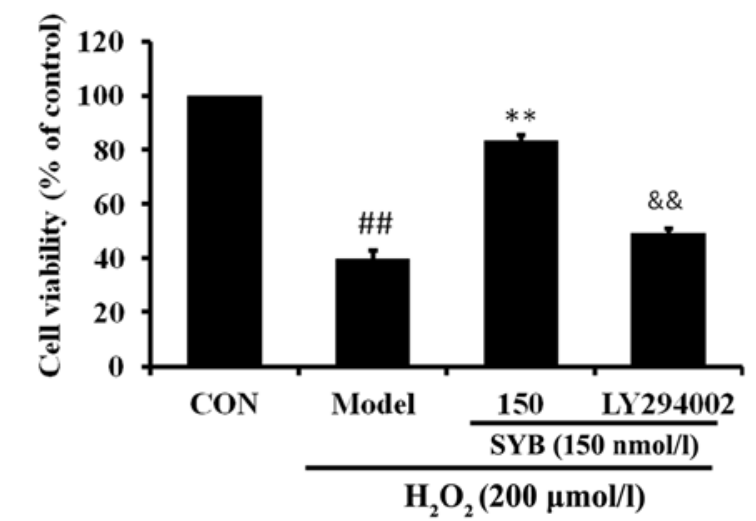

B

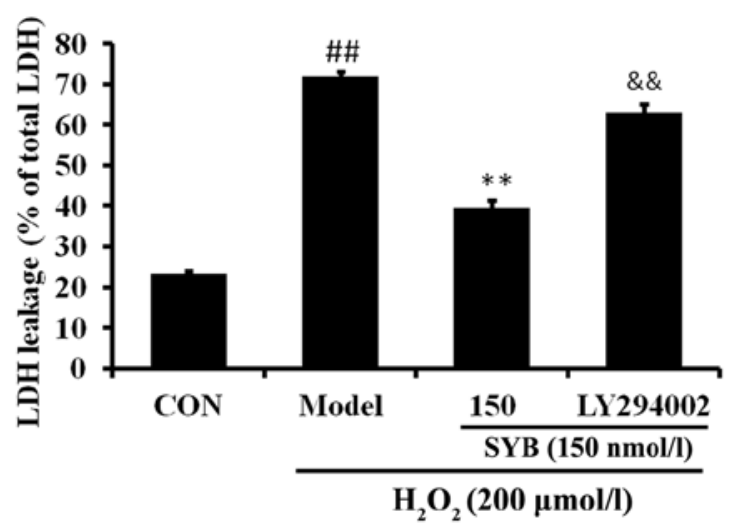

C
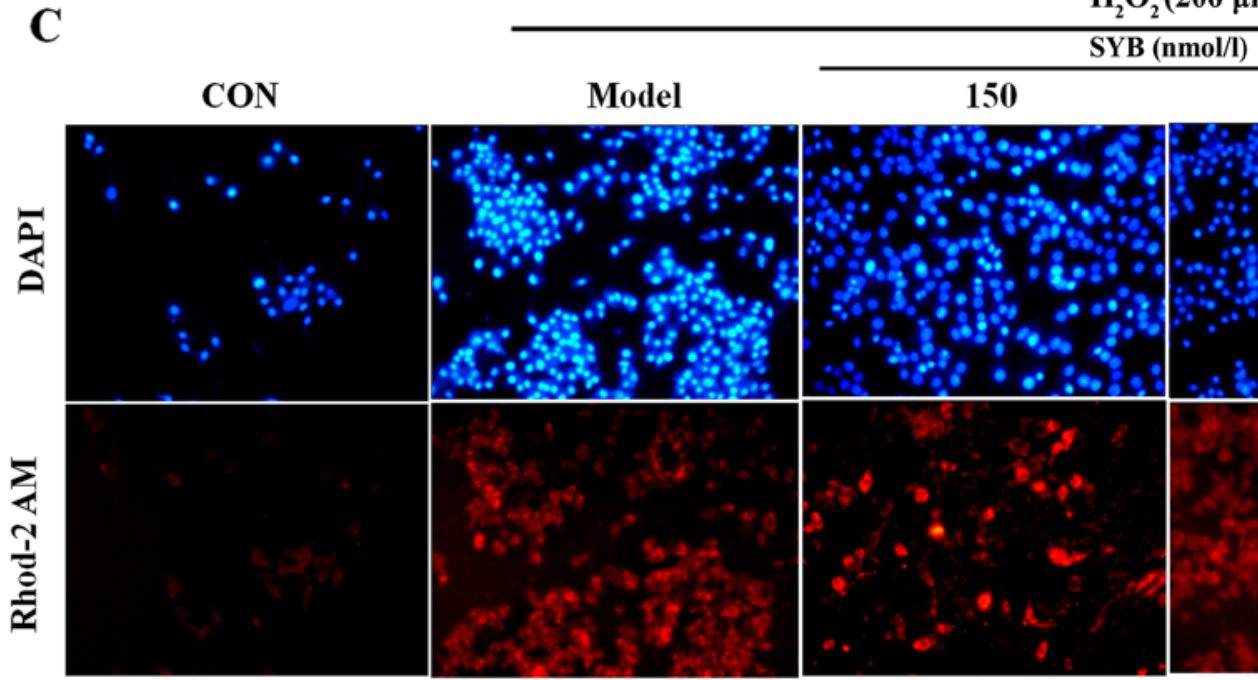

SYB (nmol/l)
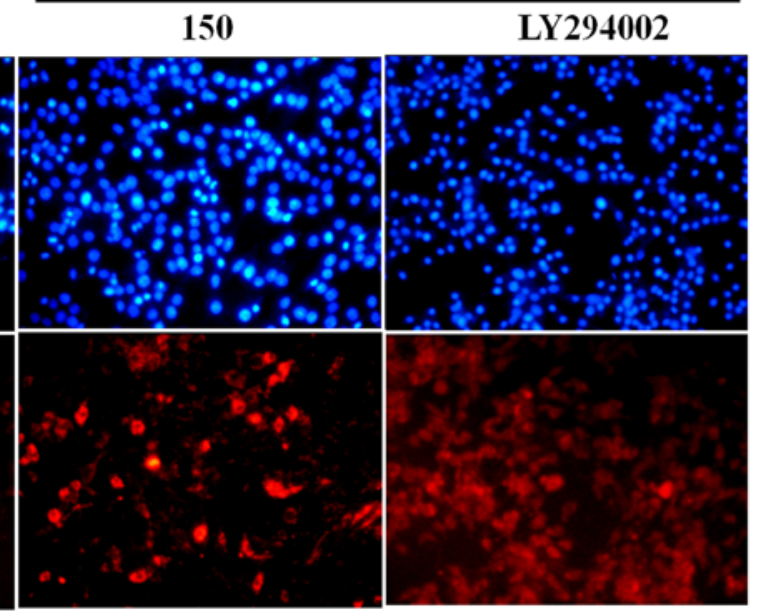

Figure 6. Effects of safflower yellow B (SYB) and LY294002 on cell viability, cell integrity and calcium overload in HepG2 cells. Cells were pre-treated with SYB $(150 \mathrm{nmol} / \mathrm{l})$ or LY294002 $(10 \mu \mathrm{M})$ for $24 \mathrm{~h}$, then exposed to $\mathrm{H}_{2} \mathrm{O}_{2}(200 \mu \mathrm{mol} / \mathrm{l})$. (A) Cell viability was assayed by MTT assay. (B) Lactate dehydrogenase (LDH) leakage (\% of total LDH) was assayed as described in the Materials and methods. (C) The representative staining for Rhod-2 AM (red signal, specific for mitochondrial calcium) and DAPI (blue signal) are shown by confocal microscopy. The image panels are representative of the best of 3 independent image acquisitions. ${ }^{\# \#} \mathrm{P}<0.01$, statistically significant difference between model vs. control group; ${ }^{* *} \mathrm{P}<0.01$, statistically significant difference between $\mathrm{SYB}$ vs. model group; \& $\mathrm{P}<0.01$, statistically significant difference between LY294002 vs. SYB group.

in the pathogenesis of hepatic ischaemia/reperfusion $(\mathrm{I} / \mathrm{R})$ injury. Previous research has indicated that although ROS are generated mainly as by-products of mitochondrial respiration (as the primary cellular consumer of oxygen, together with multiple electron carriers and redox enzymes), they are themselves extremely susceptible to oxidative damage (23). The overproduction of ROS leads to lipid peroxidation, damage to the mitochondrial membrane, the release of mitochondrial apoptogenic factors into the cytoplasm, followed by caspase activation and finally, cell apoptosis (24). Natural antioxidants that inhibit ROS generation are considered essential in terms of protecting the liver from chemical- or I/R-induced damage. Consequently, previous research has focused on natural antioxidants that have chemopreventive properties and on their mechanisms of action (25).

In a previous study, it was demonstrated that SYB is able to significantly attenuate brain injury induced by ischemia, and it was pointed out that SYB exerts neuroprotective effects against brain injury induced by ischemia by increasing the activities of antioxidant enzymes in the brain tissue, thus decreasing free radical generation and improving mitochondrial function (15). However, to the best of our knowledge, there are no studies available to date on the effects of SYB on I/R- or $\mathrm{H}_{2} \mathrm{O}_{2}$-induced oxidative stress in liver cells. Thus, in the present study, we examined the inhibitory effects of SYB on $\mathrm{H}_{2} \mathrm{O}_{2}$-induced injury to HepG2 cells. The results revealed that the exposure of HepG2 cells to $\mathrm{H}_{2} \mathrm{O}_{2}$ significantly decreased cell viability and increased the release of $\mathrm{LDH}$, and pre-treatment of the cells with SYB increased cell viability and reduced the release of LDH, implying that SYB has the ability to protect HepG2 cells from $\mathrm{H}_{2} \mathrm{O}_{2}$-induced injury. In addition, we established that the ability of SYB to modulate important proteins of the cell signaling cascades is directly involved in its protective effects.

Oxidative stress-induced cell injury is associated with increases in ROS, such as $\mathrm{H}_{2} \mathrm{O}_{2}$, hydroxyl radicals, superoxide anion, singlet oxygen, nitric oxide and peroxynitrites (26). Lipid peroxidation of polyunsaturated fatty acid produces ROS and toxic aldehydes, such as 4-hydroxy-2-nonenal (4-HNE) and MDA (27). Therefore, the concentration of MDA in cells or tissue lysates is considered to be a major cause of lipid peroxi- 
dation. In this study, we demonstrated that exposure to $\mathrm{H}_{2} \mathrm{O}_{2}$ induced the overproduction of ROS in hepatic cells and led to oxidative stress; however, treatment with SYB significantly suppressed $\mathrm{H}_{2} \mathrm{O}_{2}$-induced ROS generation and lipid peroxidation, possibly due to the powerful antioxidant and free radical scavenging activity of SYB.

It has previously been noted that oxidants not only stimulate inflammatory cytokines in HepG2 cells and cause cellular senescence, but also induce the apoptosis of HepG2 cells, and certain apoptotic agents increase the production of ROS in mitochondria (28), and antioxidants such as NAC and vitamin E prevent cell apoptosis. Apoptosis is programmed cell death and it plays an important role in embryogenesis, metamorphosis and cellular homeostasis (29). In this study, we discovered that $\mathrm{H}_{2} \mathrm{O}_{2}$ induced the apoptosis of HepG2 cells using flow cytometry. SYB markedly decreased the apoptosis induced by $\mathrm{H}_{2} \mathrm{O}_{2}$ in a dose-dependent manner, and these results were verified by determining the caspase-3 levels.

Mitochondria are an important source of ROS within the majority of mammalian cells. Excessive ROS production contributes to mitochondrial damage in a wide range of pathologies (30). Damaged mitochondria can then cause defects in lipid homeostasis, bioenergetics and ROS production, leading to lipid accumulation and oxidative stress (31). Increasing evidence suggests that $\Delta \Psi \mathrm{m}$ assay can be used as a more specific test for early mitochondrial injury (32). In the present study, using JC-1, we revealed that $\mathrm{H}_{2} \mathrm{O}_{2}$ induced the loss of $\Delta \Psi \mathrm{m}$ in HepG2 cells. Pre-treatment with SYB for $24 \mathrm{~h}$ restored the $\Delta \Psi \mathrm{m}$ to the basal level. These findings implied that the ability of SYB to attenuate oxidative stress partly depends on inhibiting mitochondrial-related apoptosis.

Oxidative stress caused by ROS is responsible for a wide variety of cellular damage and is the most validated mechanism of secondary injury (33). Following oxidative stress, the overproduction of ROS, and subsequently the depletion of antioxidants, results in the total breakdown of the endogenous antioxidant defense mechanisms, culminating in failure to protect cells from damage induced by oxidative stress. SOD is an oxygen radical scavenger that scavenges superoxide radicals by converting them into $\mathrm{H}_{2} \mathrm{O}_{2}$, which is then converted to water by catalase and GSH-Px (34). In our study, exposure of the HepG2 cells to $\mathrm{H}_{2} \mathrm{O}_{2}$ induced a marked decrease in the concentration of SOD and GSH-Px, which was reversed by pretreatment with SYB for $24 \mathrm{~h}$.

Nrf2, a basic leucine zipper (bZIP) transcription factor that belongs to the cap'n'collar (CNC) family, plays an important role in the transcriptional regulation of phase II enzymes (35). The Nrf2-activating pathway provides a rapid feedback triggered mechanism through which the cell is challenged by oxidative stress (36). Upon stimulation, Nrf2 disassociates from its cytosolic inhibitor, Keap-1, and translocates into the nucleus, then binds to the ARE in the promoter regions of many phase II enzymes, including HO-1 and NQO1 (37). As the Nrf2/ARE pathway has been shown to provide protection against several oxidative impacts in different organs, the induction of HO-1 and NQO1 under the regulation of Nrf2/ ARE may provide a therapeutic option for liver diseases in cases of severe oxidative stress (38). We hypothesized that the increased protein expression level of HO-1 and NQO1 was due to activation of the Nrf-2 signaling pathway. As expected,
SYB had the effect of activating Nrf2, which led to the increased protein expression of HO-1 and NQO1.

Previous research has demonstrated that a wide variety of phytochemicalsfromnatural products, suchasbutinand3',4'-didemethylnobiletin protect against oxidative stress-induced cell damage through the PI3K/AKT/Nrf2-dependent pathway (39). Therefore, we investigated whether that pathway contributes to the protective effects of SYB against $\mathrm{H}_{2} \mathrm{O}_{2}$-induced oxidative stress. Importantly, the phosphorylation of AKT was significantly increased in the SYB-treated cells, and the inhibition of AKT signaling by the AKT inhibitor, LY294002, blocked the SYB-induced protein expression of Nrf2 and HO-1 and reduced the expression level of GSK-Px and SOD. Further analysis also indicated that LY294002 abolished the ability of SYB to control the calcium levels which were significantly increased by $\mathrm{H}_{2} \mathrm{O}_{2}$. These results indicate that AKT/Nrf2 signaling is involved in the cytoprotective effects of SYB.

In conclusion, the findings of this study demonstrate that pre-treatment with SYB leads to the protection of hepatic cells against $\mathrm{H}_{2} \mathrm{O}_{2}$-induced oxidative stress through a mechanism that involves Nrf2 activation and the upregulation of the expression of its downstream antioxidant genes, mediated by AKT. These results provide a scientific basis for the hepatoprotective effects of pure compound SYB derived from Safflower and suggest tht it may be of therapeutic value in the treatment of various liver diseases associated with oxidative stress.

\section{Acknowledgements}

This study was supported by the National Science Foundation of China (nos. 81173514 and 81302695).

\section{References}

1. Willcox JK, Ash SL and Catignani GL: Antioxidants and prevention of chronic disease. Crit Rev Food Sci Nutr 44: 275-295, 2004

2. Cui K, Luo X, Xu K and Ven Murthy MR: Role of oxidative stress in neurodegeneration: Recent developments in assay methods for oxidative stress and nutraceutical antioxidants. Prog Neuropsychopharmacol Biol Psychiatry 28: 771-799, 2004.

3. Reuter S, Gupta SC, Chaturvedi MM and Aggarwal BB Oxidative stress, inflammation, and cancer: how are they linked? Free Radic Biol Med 49: 1603-1616, 2010.

4. Bitar MS, Al-Saleh E and Al-Mulla F: Oxidative stress - mediated alterations in glucose dynamics in a genetic animal model of type II diabetes. Life Sci 77: 2552-2573, 2005.

5. Coskun O, Ocakci A, Bayraktaroglu T and Kanter M: Exercise training prevents and protects streptozotocin-induced oxidative stress and beta-cell damage in rat pancreas. Tohoku J Exp Med 203: 145-154, 2004.

6. Llovet JM, Burroughs A and Bruix J: Hepatocellular carcinoma. Lancet 362: 1907-1917, 2003.

7. Tien Kuo M and Savaraj N: Roles of reactive oxygen species in hepatocarcinogenesis and drug resistance gene expression in liver cancers. Mol Carcinog 45: 701-709, 2006.

8. Zhu R, Wang Y, Zhang L and Guo Q: Oxidative stress and liver disease. Hepatol Res 42: 741-749, 2012.

9. Palter R, Lundin RE and Haddon WF: A cathartic lignan glycoside isolated from Carthamus tinctorius. Phytochemistry 11: 2871-2874, 1972.

10. Kazuma K, Takahashi T, Sato K, Takeuchi H, Matsumoto T and Okuno T: Quinochalcones and flavonoids from fresh florets in different cultivars of Carthamus tinctorius L. Biosci Biotechnol Biochem 64: 1588-1599, 2000.

11. Akihisa T, Yasukawa K, Oinuma H, Kasahara Y, Yamanouchi S, Takido M, Kumaki K and Tamura T: Triterpene alcohols from the flowers of compositae and their anti-inflammatory effects. Phytochemistry 43: 1255-1260, 1996. 
12. Wakabayashi T, Hirokawa S, Yamauchi N, Kataoka T, Woo JT and Nagai K: Immunomodulating activities of polysaccharide fractions from dried safflower petals. Cytotechnology 25: 205-211, 1997.

13. Duan JL, Wang JW, Guan Y, Yin Y, Wei G, Cui J, Zhou D, Zhu YR, Quan W, Xi MM and Wen AD: Safflor yellow A protects neonatal rat cardiomyocytes against anoxia/reoxygenation injury in vitro. Acta Pharmacol Sin 34: 487-495, 2013.

14. Zheng WC, Chen DB, Li B and Zhang L: The preventive effects of safflor yellow on myocardium injury of myocardium ischemic reperfusion in rats. Chin Pharmacol Bull 19: 1032-1034, 2003.

15. Wang C, Zhang D, Li G, Liu J, Tian J, Fu F and Liu K: Neuroprotective effects of safflor yellow B on brain ischemic injury. Exp Brain Res 177: 533-539, 2007.

16. Cohen GM: Caspases: the executioners of apoptosis. Biochem J 326(Pt 1): 1-16, 1997.

17. Kwong JQ, Henning MS, Starkov AA and Manfredi G: The mitochondrial respiratory chain is a modulator of apoptosis. J Cell Biol 179: 1163-1177, 2007.

18. Adam-Vizi V and Chinopoulos C: Bioenergetics and the formation of mitochondrial reactive oxygen species. Trends Pharmacol Sci 27: 639-645, 2006.

19. Campbell MR, Karaca M, Adamski KN, Chorley BN, Wang X and Bell DA: Novel hematopoietic target genes in the NRF2mediated transcriptional pathway. Oxid Med Cell Longev 2013: 120305, 2013.

20. Xu D, Hu L, Xia X, Song J, Li L, Song E and Song Y: Tetrachlorobenzoquinone induces acute liver injury, up-regulates $\mathrm{HO}-1$ and NQO1 expression in mice model: the protective role of chlorogenic acid. Environ Toxicol Pharmacol 37: 1212-1220, 2014.

21. Lee YJ, Jeong HY, Kim YB, Lee YJ, Won SY, Shim JH, Cho MK, Nam HS and Lee SH: Reactive oxygen species and PI3K/Akt signaling play key roles in the induction of Nrf2-driven heme oxygenase-1 expression in sulforaphane-treated human mesothelioma MSTO-211H cells. Food Chem Toxicol 50: 116-123, 2012.

22. Okezie IA: Free radicals, oxidative stress, and antioxidants in human health and disease. J Am Oil Chem Soc 75: 199-212, 1998.

23. Fiskum G, Rosenthal RE, Vereczki V, Martin E, Hoffman GE, Chinopoulos $\mathrm{C}$ and Kowaltowski A: Protection against ischemic brain injury by inhibition of mitochondrial oxidative stress. J Bioenerg Biomembr 36: 347-352, 2004

24. Ghosh M, Manna P and Sil PC: Protective role of a coumarinderived schiff base scaffold against tertiary butyl hydroperoxide (TBHP)-induced oxidative impairment and cell death via MAPKs, NF- $\kappa$ B and mitochondria-dependent pathways. Free Radic Res 45: 620-637, 2011.

25. Masella R, Di Benedetto R, Varì R, Filesi C and Giovannini C: Novel mechanisms of natural antioxidant compounds in biological systems: involvement of glutathione and glutathionerelated enzymes. J Nutr Biochem 16: 577-586, 2005.
26. Trachootham D, Lu W, Ogasawara MA, Nilsa RD and Huang P: Redox regulation of cell survival. Antioxid Redox Signal 10: 1343-1374, 2008.

27. Negre-Salvayre A, Coatrieux C, Ingueneau C and Salvayre R: Advanced lipid peroxidation end products in oxidative damage to proteins. Potential role in diseases and therapeutic prospects for the inhibitors. Br J Pharmacol 153: 6-20, 2008.

28. Kroemer G and Reed JC: Mitochondrial control of cell death. Nat Med 6: 513-519, 2000.

29. Renehan AG, Booth C and Potten CS: What is apoptosis, and why is it important? BMJ 322: 1536-1538, 2001.

30. Murphy MP. How mitochondria produce reactive oxygen species. Biochem J 417: 1-13, 2009.

31. Serviddio G, Bellanti F, Sastre J, Vendemiale G and Altomare E: Targeting mitochondria: a new promising approach for the treatment of liver diseases. Curr Med Chem 17: 2325-2337, 2010.

32. Jiang J, Yu S, Jiang Z, Liang C, Yu W, Li J, Du X, Wang H, Gao X and Wang $\mathrm{X}$ : N-acetyl-serotonin protects HepG2 cells from oxidative stress injury induced by hydrogen peroxide. Oxid Med Cell Longev 2014: 310504, 2014.

33. Wang CC, Fang KM, Yang CS and Tzeng SF: Reactive oxygen species-induced cell death of rat primary astrocytes through mitochondria-mediated mechanism. J Cell Biochem 107: 933-943, 2009

34. Kondo T, Higashiyama Y, Goto S, Iida T, Cho S, Iwanaga M, Mori K, Tani M and Urata Y: Regulation of gamma-glutamylcysteine synthetase expression in response to oxidative stress. Free Radic Res 31: 325-334, 1999.

35. Ryter SW, Alam J and Choi AMK: Heme oxygenase-1/carbon monoxide: from basic science to therapeutic applications. Physiol Rev 86: 583-650, 2006.

36. Okawa H, Motohashi H, Kobayashi A, Aburatani H, Kensler TW and Yamamoto M: Hepatocyte-specific deletion of the keap1 gene activates Nrf2 and confers potent resistance against acute drug toxicity. Biochem Biophys Res Commun 339: 79-88, 2006.

37. Kay HY, Won Yang J, Kim TH, Lee da Y, Kang B, Ryu JH, Jeon R and Kim SG: Ajoene, a stable garlic by-product, has an antioxidant effect through Nrf2-mediated glutamate-cysteine ligase induction in HepG2 cells and primary hepatocytes. J Nutr 140: 1211-1219, 2010.

38. Na HK, Kim EH, Jung JH, Lee HH, Hyun JW and Surh YJ: (-)-Epigallocatechin gallate induces Nrf2-mediated antioxidant enzyme expression via activation of PI3K and ERK in human mammary epithelial cells. Arch Biochem Biophys 476: 171-177, 2008.

39. Su JD, Yen JH, Li S, Weng CY, Lin MH, Ho CT and Wu MJ: 3',4'-Didemethylnobiletin induces phase II detoxification gene expression and modulates PI3K/Akt signaling in PC12 cells. Free Radic Biol Med 52: 126-141, 2012. 